\title{
Aquaporin-2 and urea transporter-A1 are up-regulated in rats with Type I diabetes mellitus
}

\author{
P. Bardoux ${ }^{1}$, M. Ahloulay ${ }^{2}$, S. Le Maout ${ }^{3}$, L. Bankir ${ }^{1}$, M.-M.Trinh-Trang-Tan ${ }^{3}$ \\ ${ }^{1}$ INSERM Unit 367, Paris, France \\ ${ }^{2}$ INSERM Unit 90, Paris, France \\ ${ }^{3}$ Service of Cell Biology, CEA/Saclay, Gif-sur Yvette, France
}

\section{Abstract}

Aims/hypothesis. Although the urine flow rate is considerably higher in diabetes mellitus, water reabsorption is greatly increased to concentrate an increased amount of solutes. Our study evaluated the expression of aquaporins and urea transporters, which are essential to the urinary concentration process.

Methods. Northern blot and immunoblot were used to quantify mRNA and proteins for aquaporin-2 (AQP2) as well as urea transporters UT-A1, UT-A2 and UT-B1, in subzones of the renal medulla of rats with streptozotocin-induced diabetes.

Results. In these rats, glycaemia, urine flow rate and water reabsorption were respectively fourfold, ninefold and fourfold those of control rats. The AQP2 protein isoforms were significantly up-regulated in outer and inner medulla. In the base and tip of inner medulla, UT-A1 mRNA was significantly up-regulated (three- and 1.3-fold, respectively) as well as the $117 \mathrm{kD}$ protein (ten- and threefold, respectively) whereas the $97 \mathrm{kD}$ protein was not changed or decreased twofold, respectively. This suggests that, in diabetes, the inner medullary collecting duct is endowed with more UT-A1, especially in its initial part. In the case of mRNA and proteins of UT-A2, located in thin descending limbs in the inner stripe of outer medulla, they were respectively not changed and down-regulated in diabetic rats.

Conclusion/interpretation. This study shows that in diabetes, the increased expression of AQP2 and UTA1 in medullary collecting duct is consistent with an improved concentrating activity. In addition, the underexpression of UT-A 2 and the overexpression of UT-A1 in the initial medullary collecting duct are reminiscent of the changes seen after experimental reduction of urine concentration or low protein feeding. [Diabetologia (2001) 44: 637-645]

Keywords Diabetes mellitus, streptozotocin, kidney, urinary concentrating activity, water channel, urea transporters, rat.
In diabetes mellitus, water turnover in the body is enhanced because of the glucose-induced osmotic diuresis and it is usually assumed that the concentrating capacity of the kidney is partially impaired. On the

Received: 4 October 2000 and in revised form: 10 January 2001

Corresponding author: Marie-Marcelle Trinh-Trang-Tan, CEA Saclay, DBCM/SBCe, 91191 Gif-sur-Yvette, France

Abbreviations: AQP2, Aquaporin-2; AVP, arginine vasopressin; CD, collecting duct; CO, control; dDAVP, desamino8 -arginine vasopressin; IM, inner medulla; IMCD, inner medullary collecting duct; IS, inner stripe of outer medulla; SDS, sodium dodecyl sulphate; STZ, streptozotocin; $\mathrm{T}^{\mathrm{C}} \mathrm{H} 2 \mathrm{O}$, solutefree water reabsorption; TDL, thin descending limb. other hand, plasma vasopressin concentration is known to be increased by several fold in patients with Type I (insulin-dependent) diabetes mellitus or Type II (non-insulin-dependent) diabetes mellitus as well as in animal models of experimental or genetic diabetes mellitus [1-6]. This high vasopressin concentration is accompanied by a desensitization of $\mathrm{V} 1 \mathrm{a}$ receptors in liver, kidney and platelets $[7,8]$. In contrast, renal V2 receptors, responsible for the antidiuretic action of the hormone, are not down-regulated [8].

Actually, higher vasopressin in diabetes mellitus probably represents an appropriate adaptation by limiting to some extent the amount of water required 
for the urinary excretion of a much increased load of solutes (due in large part because of glucose wastage). Recent studies have revealed that the diabetic kidney displays an increased (not a decreased) urinary concentrating activity. Although urine flow rate is much increased and urine osmolality modestly decreased, the amount of free water that the kidney reabsorbs in order to excrete the actual load of solutes, the solute-free water reabsorption, is largely enhanced in diabetes mellitus $[9,10]$.

The influence of vasopressin on urinary concentrating activity is largely because of the effect of this hormone on the permeability of the collecting duct (CD) to water, depending on the vasopressin-regulated water channel aquaporin-2 (AQP2). It is also critically dependent on the accumulation of urea in the inner medulla which is made possible by the presence, in the terminal part of the $\mathrm{CD}$, of a vasopressin-dependent urea transporter, UT-A1. This transporter allows urea to diffuse into the inner medullary interstitium, thus feeding urea continuously to the deepest part of the medulla. In addition, medullary urea, which might escape this region by ascending the vasa recta, is returned to the inner medulla by countercurrent exchange in descending thin limbs and vasa recta endowed with facilitated urea transporters (UTs) UT-A2 and UT-B1, respectively [11-15]. Both UT-A1 and UT-A2 are expressed exclusively in the kidney and are encoded by differential transcription from the same gene. Both UT-A2 and UT-B1 are present on the luminal and the basolateral membranes along a limited length of thin descending limbs (TDL) for UT-A2 [16] and in the endothelium of descending vasa recta along most of their length for UT-B1 [17].

Because of the unique situation encountered in diabetes mellitus, with, simultaneously, a large increase in both urine flow rate and vasopressin-dependent water reabsorption, it was interesting to see whether this disease is associated with alterations in the expression of AQP2 and of the urea transporters involved in the urinary concentrating process. Our experiments were designed to better characterise the relative amounts of the different solutes that are concentrated in the urine of diabetes mellitus rats and to evaluate, in the same rats, the changes in AQP2 and urea transporter mRNA or proteins occuring in diabetes mellitus.

\section{Material and methods}

Animals and induction of diabetes mellitus. Principles of laboratory animal care were followed. Adult male Wistar rats (Iffa Credo, Lyon, France) were used. Because diabetes slows the increase in body weight with time, those rats which were to be made diabetic weighed $50 \mathrm{~g}$ more than control rats at the start of the experiment, so that they would reach similar body weights at the time of killing. Rats were allowed free ac- cess to tap water and regular rat food (M5, Extralabo, Provins, France), containing $23 \%$ protein, during the entire experiment. Different rats were used for northern and western blot analysis.

Diabetes was induced by a single intraperitoneal injection of streptozotocin (STZ) (Sigma, St Louis, Mo., USA), $65 \mathrm{mg}$ / $\mathrm{kg}$ body weight, freshly dissolved in $0.1 \mathrm{mmol} / \mathrm{l}$ citrate buffer, $\mathrm{pH}$ 4.5. Control (CO) rats were injected with vehicle alone. Two days later, diabetes was confirmed by measuring the presence of glucose in urine. Two weeks after the streptozotocin (STZ) injection, rats were placed in individual metabolic cages for 1 week and urine was collected for the last 2 days $(2 \cdot 24 \mathrm{~h})$. Urinary flow rate, osmolality and glucose and urea concentrations were measured. Rats were killed 3 weeks after streptozotocin or vehicle administration. This duration of diabetes mellitus was chosen because several parameters perturbated by the initiation of diabetes mellitus reach a steady state 2 weeks after STZ injection [9]. Rats were anaesthetised with pentobarbital and a blood sample was collected from the jugular vein. Blood glucose was measured with One-touch-two (Life-Scan, Issy-Les-Moulineaux, France), plasma and urine osmolality with a freezing-point osmometer (Roebling, Berlin, Germany), glycosuria with a Glucose kit (Trinder, Sigma, St Louis, USA), and plasma and urine urea concentrations with a Urea kit (BioMérieux, Lyon, France). Solute-free water reabsorption was calculated according to the following formula:

$\mathrm{T}_{\mathrm{H} 2 \mathrm{O}}^{\mathrm{c}}=((\mathrm{Uosm} / \mathrm{Posm}) \cdot$ urine flow rate $)$-urine flow rate

Dissection of renal medulla subzones. Because urea transporters are not expressed in the renal cortex and outer stripe of the outer medulla, only the inner stripe of outer medulla (IS) and the inner medulla (IM) were studied. In these two zones, urea transporters are not expressed homogeneously. In IS, UT-A2 has been localized in the deep but not in the superficial half of thin descending limb (TDL) of short loops of Henle [14, $16,18]$. In IM, facilitated urea transport has been shown in the terminal but not in the initial inner medullary collecting duct (CD) (IMCD) [19] and UT-A1 mRNA have been localized in IM tip but not in IM base [18]. Accordingly, in this study, IS and IM were each divided into two subregions to allow a more precise spatial analysis.

Kidneys were removed, weighed and sliced. For both northern blot and western blot experiments, representative tissue fragments $(15-50 \mathrm{mg})$ of the upper and lower halves of IS (superficial and deep IS, respectively) and of the upper third and the lower two thirds of IM (base and tip, respectively) were dissected from kidney slices at $4{ }^{\circ} \mathrm{C}$ under stereomicroscopic observation.

Northern blot analysis of urea transporters. Northern blot analysis was done in 5 diabetic rats and 4 control rats. Total RNA was extracted from homogenised tissue fragments by a simplified guanidium thiocyanate procedure (RNA NOW, Biogentex, Seabrook, USA). Quantification of UT-A1 and UTA2 mRNA was done using a rat clone of $771 \mathrm{bp}$ which reveals UT-A1 as a $4.0 \mathrm{~kb}$-transcript, and UT-A2 as a $3.0 \mathrm{~kb}$-transcript [20]. The UT-B1 mRNA was revealed by a rat clone of $1200 \mathrm{bp}$ [21]. Probes were radiolabeled by the random-priming technique (Megaprime labeling kit, Amersham, Les Ulis, France) using $[\alpha-32 \mathrm{P}] \mathrm{dCTP}$, to a specific activity of $2 \cdot 10^{9} \mathrm{cpm} / \mu \mathrm{g}$ cDNA. The RNA samples $(5 \mu \mathrm{g})$ were denatured and separated by electrophoresis on agarose gel (1.0\%) containing $0.6 \mathrm{~mol} / \mathrm{l}$ formaldehyde. The RNAs were transferred overnight from gel to nitrocellulose membranes (Hybond C-Extra, Amersham, Ulis, France) which were then baked in a vacuum oven $\left(2 \mathrm{~h}, 80^{\circ} \mathrm{C}\right)$. Blots were placed in glass hybridization tubes containing $10 \mathrm{ml}$ medium composed of $5 \cdot$ SSPE (see 
Table 1. Body and kidney weight and functional parameters in control (CO) and diabetic rats (diabetes mellitus) rats

\begin{tabular}{|c|c|c|c|c|c|}
\hline & & $\mathrm{CO}$ & DM & $\mathrm{DM} / \mathrm{CO}$ & $p$ \\
\hline Body weight & $\mathrm{g}$ & $316 \pm 17$ & $295 \pm 8$ & 0.93 & NS \\
\hline Kidney weight & $\mathrm{mg} / 100 \mathrm{~g} \mathrm{BW}$ & $634 \pm 20$ & $1025 \pm 26$ & 1.62 & $<0.001$ \\
\hline Plasma osmolality & $\mathrm{mOsm} / \mathrm{kg} \mathrm{H}_{2} \mathrm{O}$ & $304 \pm 4$ & $333 \pm 3$ & 1.10 & $<0.001$ \\
\hline Urine flow rate & $\mathrm{ml} /$ day & $17 \pm 3$ & $150 \pm 21$ & 8.82 & $<0.001$ \\
\hline Urine osmolality & $\mathrm{mOsm} / \mathrm{kg} \mathrm{H}{ }_{2} \mathrm{O}$ & $1502 \pm 134$ & $956 \pm 32$ & 0.64 & $<0.001$ \\
\hline Osmolar excretion & mosm/day & $23 \pm 3$ & $140 \pm 19$ & 6.09 & $<0.001$ \\
\hline \multicolumn{6}{|l|}{ Urea } \\
\hline Plasma urea concentration & $\mathrm{mmol} / \mathrm{l}$ & $8.4 \pm 0.7$ & $10.5 \pm 0.7$ & 1.25 & NS \\
\hline Urine urea concentration & $\mathrm{mmol} / \mathrm{l}$ & $754 \pm 55$ & $204 \pm 26$ & 0.27 & $<0.001$ \\
\hline Urea excretion & $\mathrm{mmol} /$ day & $11.7 \pm 1.5$ & $26.8 \pm 2.4$ & 2.29 & $<0.001$ \\
\hline Urea excretion & $\%$ of total solutes & $47 \pm 2$ & $15 \pm 1$ & 0.33 & $<0.001$ \\
\hline Urine $_{\text {urea }} /$ Plasma $_{\text {urea }}$ & & $93 \pm 9$ & $19 \pm 2$ & 0.20 & $<0.001$ \\
\hline Urine $_{\text {glucose }} /$ Blood $_{\text {glucose }}$ & & 0 & $21 \pm 2 *$ & & $<0.001$ \\
\hline
\end{tabular}

Values are means \pm SEM of 8 control and 10 diabetes mellitus rats ( $* n=5$ rats only)

$\mathrm{BW}=$ body weight

composition below), $50 \%$ formamide, $0.5 \%$ sodium dodecyl sulphate (SDS), $1 \mathrm{mg} / \mathrm{ml}$ bovine serum albumin, $1 \mathrm{mg} / \mathrm{ml}$ Ficoll $400,1 \mathrm{mg} / \mathrm{ml}$ polyvynylpyrrolidone, and $40 \mu \mathrm{g} / \mathrm{ml}$ denatured salmon sperm DNA. Prehybridization was done at $42^{\circ} \mathrm{C}$ for $4 \mathrm{~h}$ in a hybridization oven. Then, the radiolabeled probe was added to prehybridization medium $\left(4 \cdot 10^{6} \mathrm{cpm} / \mathrm{ml}\right)$, and membranes were incubated overnight at $42^{\circ} \mathrm{C}$. Blots were washed twice at $23^{\circ} \mathrm{C}$ in $2 \cdot \mathrm{SSPE}, 0.1 \% \mathrm{SDS}$ for $15 \mathrm{~min}$ and once at $32^{\circ} \mathrm{C}$ in $1 \cdot \mathrm{SSPE}, 0.1 \% \mathrm{SDS}$ for $30 \mathrm{~min}$. The final wash was carried out at $55^{\circ} \mathrm{C}$ for UT-A 1 and UT-A2, and $42{ }^{\circ} \mathrm{C}$ for UT$\mathrm{B} 1$, in $0.1 \cdot \mathrm{SSPE}, 0.1 \% \mathrm{SDS}, 30 \mathrm{~min}$. The composition of $1 \cdot \mathrm{SSPE}$ was $150 \mathrm{mmol} / \mathrm{l} \mathrm{NaCl} ; 10 \mathrm{mmol} / 1 \mathrm{NaH}_{2} \mathrm{PO}_{4} ; 1 \mathrm{mmol} / \mathrm{l}$ EDTA; $\mathrm{pH}$ 7.4. Blots were exposed for 2 to 4 days to autoradiographic film (Hyperfilm-MP, Amersham) with intensifying screens, at $-80^{\circ} \mathrm{C}$. The membranes were then hybridized to a cDNA probe of mouse $\beta$-actin [22]. Expression of mRNA was quantified by densitometry (Deskan II and ScanAnalysis, Biosoft, Palo Alto, Calif., USA) after scanning of the autoradiograms (Scan Jet, Hewlett Packard, Les Ulis, France). The abundance of urea transporter mRNAs was expressed relative to that of $\beta$-actin in the same samples. The $\beta$-actin mRNA expression per $\mu \mathrm{g}$ total RNA was not different between the diabetic and control rats.

Antibodies. A purified rabbit polyclonal antibody against a Cterminal 19 amino acid sequence common to rat UT-A1 and UT-A2 was purchased from Alpha Diagnostic International (San Antonio, USA). Rabbit polyclonal antibodies against UT-B1 and AQP2 were prepared by Neosystem (Strasbourg, France), using as antigens synthetic peptides from the N-terminus sequence of rat UT-B1 (MEDIPTMVKVDRGESQILST), and from the $\mathrm{C}$-terminus sequence of rat AQP2 (CELHSPQSLPRGSKA). These have been characterised elsewhere $[23,24]$.

Western blot analysis of $A Q P-2$ and urea transporters. Western blot analysis was done in 4 diabetic rats and 4 control rats. Tissue fragments from the four medulla subzones were thoroughly homogenised in $0.5-1.0 \mathrm{ml}$ ice-cold lysis buffer $(250 \mathrm{mmol} / \mathrm{l}$ sucrose, $10 \mathrm{mmol} / \mathrm{l}$ triethanolamine, $\mathrm{pH}$ 7.6) containing $1 \mu \mathrm{g} /$ $\mathrm{ml}$ leupeptin and $100 \mu \mathrm{g} / \mathrm{ml}$ phenylmethylsulphonylfluoride. Protein concentration of the crude homogenates was measured with a BCA protein assay reagent kit (Pierce, Rockford, USA). Protein concentration was adjusted to $3 \mu \mathrm{g} / \mu \mathrm{l}$ with lysis buffer. Altogether $15 \mu \mathrm{g}$ protein of each crude homogenate were separated by electrophoresis on denaturing SDS $/ 10 \%$ polyacrylamide minigels. Proteins were transferred electrophoretically overnight to a polyvinylidene difluoride membrane (NEN, Boston, Mass., USA). Blots were blocked for $1 \mathrm{~h}$ at room temperature with $5 \%$ non-fat milk in PBS containing $0.3 \%$ Tween-20. Blots were incubated for $2 \mathrm{~h}$ at room temperature with either UT-A antibody $(0.5 \mu \mathrm{g} / \mathrm{ml})$ or UT-B1 antibody (1:2000 dilution of the antiserum). After washings, they were incubated for $1 \mathrm{~h}$ with the second antibody (goat antirabbit immunoglobulin $\mathrm{G}$ ) conjugated with horseradish peroxidase (Promega, Madison, USA). Specific proteins were revealed by enhanced chemiluminescence (NEN, Boston, Mass., USA). The pre-immune serum of the rabbit used for the UT-B1 antibody production was checked on a control blot and gave no labelling. Equal protein loading was verified by Coomassie blue staining of the membranes at the end of the experiment.

Statistics. Results are expressed as means \pm SEM. Differences between groups were analysed by Student's $t$ test. They were considered significant for a $p$ of less than 0.05 .

\section{Results}

Diabetic rats exhibited the expected hyperglycaemia, increase in osmolar excretion and renal hypertrophy. The high plasma osmolality was mainly due to glucose but urea concentration was also higher (Table 1). The urine flow rate increased by almost ninefold and urinary osmolality slightly decreased. Nonetheless, solute-free water reabsorption, the most ap- 


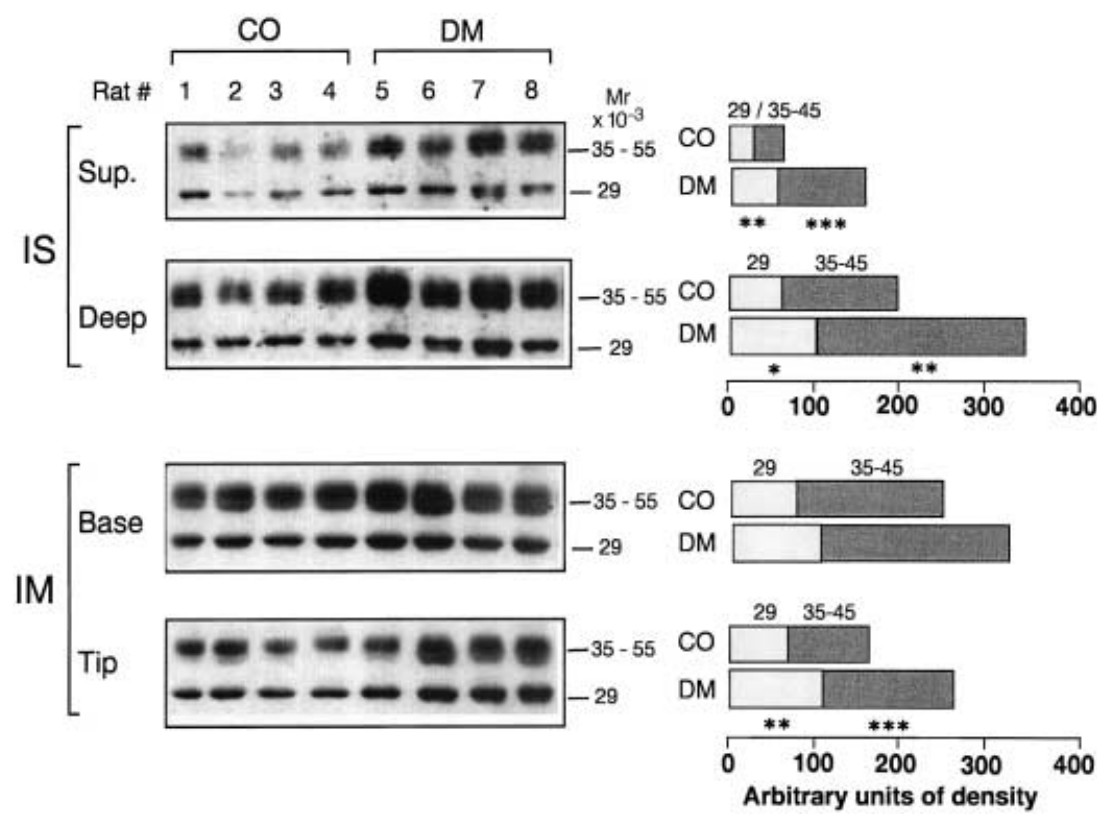

Fig. 1. Semiquantitative measurements by immunoblotting of AQP2 in diabetic (DM) and control (CO) rats. Immunoblots of homogenates from the superficial and deep halves of inner stripe of outer medulla (IS), and from base and tip of inner medulla (IM) are shown an the left panel. Each lane was loaded with $15 \mu \mathrm{g}$ of total protein. Results of densitometric analysis of these blots are shown an the right panel. Each column represents the mean of 4 rats. Stars indicate a significant difference between DM and CO rats for either non-glycosylated (29000 $\mathrm{M}_{\mathrm{r}}$ ) or glycosylated (35000-45000 $\left.\mathrm{M}_{\mathrm{r}}\right)$ forms. *: $p<0.05$; **: $p<0.01$; *** $p<0.001$

propriate index of the concentrating effort of the kidney, was considerably increased (from 61 to $269 \mathrm{ml} /$ day). This is explained by the fact that the load of osmoles concentrated in the urine is much larger in diabetic rats than in control rats $(\times 6.1)($ Table 1$)$.

The rise in osmolar excretion was mostly due to glucose which was absent in the urine of normal rats and represents as much as $58 \%$ of urinary solutes in diabetic rats. Moreover, an increase in urea excretion $(\times 2.3)$ resulting from the diabetes-associated hyperphagia also contributed to the increased osmolar excretion. It is to be noted, however, that urea represented only $15 \%$ of total solutes in diabetes mellitus compared with $47 \%$ in control rats and that its relative concentration in urine with respect to plasma (urine/plasma ratio) was fivefold lower in diabetic rats than in control rats (19 vs 93). Relative glucose concentration (urine/blood) in diabetic rats reached 21 (Table 1). Thus, in diabetes, glucose becomes the largest osmotic substance in the urine and is strongly concentrated. In contrast, urea becomes a smaller fraction of total urinary osmoles and its relative concentration is reduced when compared with control rats.

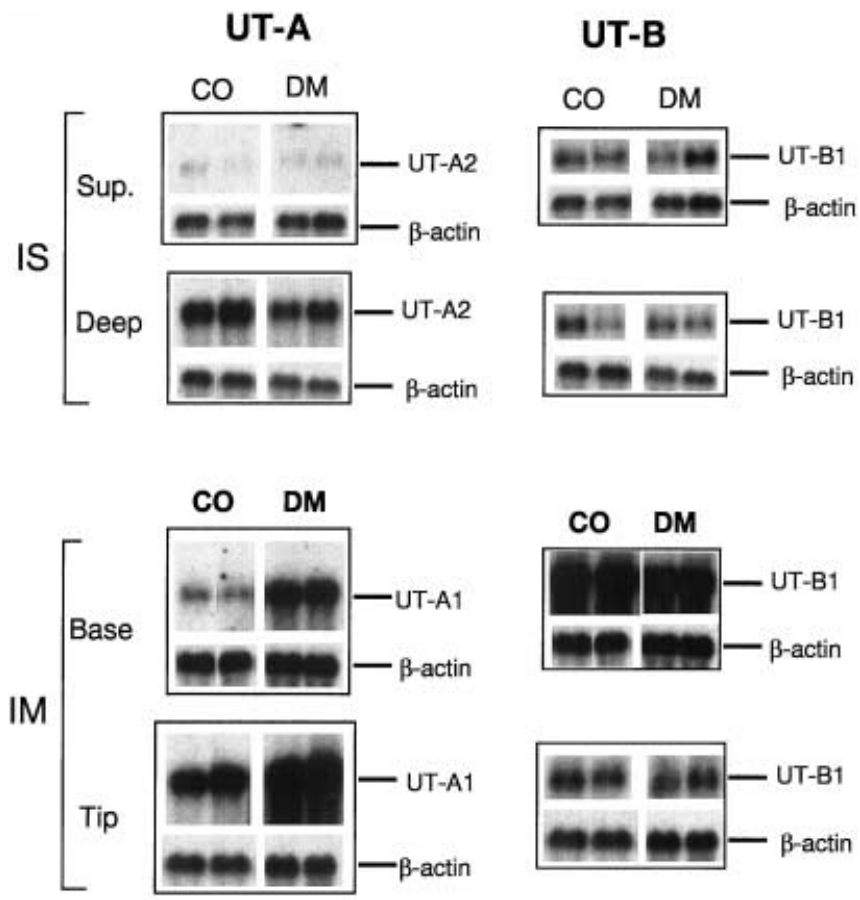

Fig. 2. Representative Northern blots of urea transporters (UT-A1, UT-A2, and UT-B1) and $\beta$-actin in superficial and deep halves of inner stripe of outer medulla (IS), and in base and tip of inner medulla (IM) of diabetic (DM) and control (CO) rats

Expression of Aquaporin 2. The abundance of AQP2 protein increased in all subregions of the medulla of diabetic rats when compared with control rats (Fig.1). These changes were more pronounced in IS than in IM (although saturation of the blots could have lead to some underestimation in diabetic rats, especially in the IM base). Both the glycosylated form (35000-45000 $\mathrm{M}_{\mathrm{r}}$ ) and the non-glycosylated 


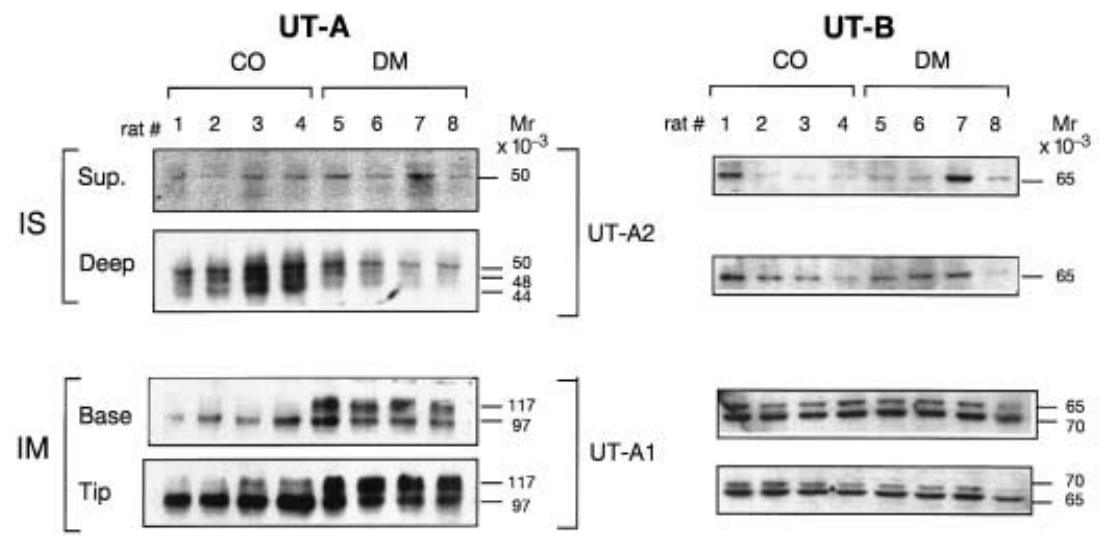

Fig. 3. Immunoblots of UT-A1, UT-A2, UT-B1 in homogenates from superficial and deep halves of inner stripe of outer medulla (IS), and from base and the tip of inner medulla (IM) of diabetic (DM) and control (CO) rats. Each lane was loaded with $15 \mu \mathrm{g}$ of total protein

form $\left(29000 \mathrm{M}_{\mathrm{r}}\right)$ were increased in similar proportions.

Expression of urea transporters. Figure 2 and 3 respectively show representative northern and western blots for the three urea transporters. As already described, UT-A1 mRNA in normal rats was abundantly expressed in the tip IM and showed only a weak expression in the base of IM. In diabetic rats, UTA1 message increased in both parts of the IM but to a much larger extent in the base $(\times 2.8)$ than in the tip ( $\times 1.2)$ (Fig. 2 and 4$)$. The changes in total protein (97000 plus $117000 \mathrm{M}_{\mathrm{r}}$ ) abundance in base and tip were similar to those in mRNA $(\times 3.2$ and 1.5 , respectively) (Fig. 4). The 97000 and $117000 \mathrm{M}_{\mathrm{r}}$ isoforms of UT-A1 were not, however, influenced to the same extent in the base, and changed in opposite direction in the tip of IM. The considerable increase in total protein observed in IM base was mostly accounted for by an eightfold increase in the 117000 $M_{r}$ isoform whereas the $97000 M_{r}$ isoform hardly changed. In the IM tip, the abundance of the 97000 $M_{r}$ was decreased about twofold in diabetes whereas that of the $117000 \mathrm{M}_{\mathrm{r}}$ was more than tripled. The $117000 \mathrm{M}_{\mathrm{r}}$ form thus became the dominant protein in the IM in diabetic rats. The opposite changes of the two isoforms suggest that part of the $97000 \mathrm{M}_{\mathrm{r}}$ form was converted to the $117000 \mathrm{M}_{\mathrm{r}}$ form by additional glycosylation.

UT-A2 is mainly expressed in the deep IS. Diabetic rats exhibited a decline in the three UT-A2 protein isoforms (Fig. 3 and 4) but the corresponding message was not altered (Fig. 2 and 4).

The mRNA of the vascular urea transporter UTB1 was expressed in the four medullary subregions with the highest expression in the IM base (Fig.5).
The corresponding protein was represented in IM by two isoforms of 65000 and $70000 \mathrm{M}_{\mathrm{r}}$ whereas only the $65000 \mathrm{M}_{\mathrm{r}}$ isoform was detectable in IS (Fig.2). Neither the mRNA nor the protein abundance of UT-B1 were influenced by diabetes (Fig.2, 3 , and 5).

\section{Discussion}

In our study, we examined the consequences of established diabetes mellitus on the expression of AQP2 and UTs in different renal medullary zones. The results reveal that, in uncontrolled diabetic rats, the expression of two proteins critical for the vasopressindependent urinary concentrating process, AQP2 and UT-A1, is considerably increased in the renal medulla. This increase occurs in a situation characterised by an enhanced vasopressin secretion [1-3] and an increased need for water conservation. Actually, as already mentioned $[9,10]$, the diabetic kidney achieves a considerable success in concentrating a large amount of glucose in the urine. This is evidenced by the 4.4-fold higher solute-free water reabsorption occurring in diabetic rats compared with control rats, even though urine flow rate is increased and urine osmolality decreased.

$A Q P 2$. Using semiquantitative immunoblotting, other investigators observed equal AQP2 abundance in total cell lysate of the tip of inner medulla in control and 3-day diabetic rats [25]. On the other hand, one preliminary report shows a significant $41 \%$ increase in AQP2 protein in whole kidney membranes of diabetic rats [26]. Our study reveals that the increased abundance in AQP2 protein occurs in all subzones of the medulla and is much more pronounced in inner stripe than in inner medulla. Although cortex and outer stripe were not examined, it is reasonable to assume that AQP2 overexpression also occured in these zones inasmuch as the bulk of water reabsorption is known to occur in the cortical part of the collecting duct. But this overexpression could probably not be detected in cortex homogenates because col- 


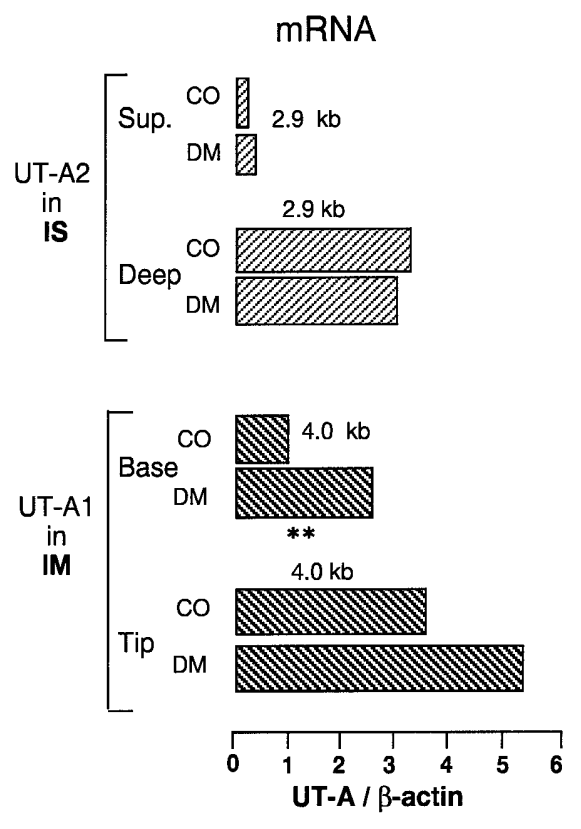

Fig.4. Densitometry analysis of UT-A 1 and UT-A 2 mRNA (left) and protein isoform (right) abundance in superficial and deep halves of inner stripe of outer medulla (IS), and in base and tip of inner medulla (IM) of diabetic (DM) and control (CO) rats. The abundance of mRNA is expressed relative to that of $\beta$-actin. Each column represents the mean of 4-5 rats per group. Stars indicate a significant difference between DM and CO rats. *: $p<0.05 ; * *: p<0.01 ; * * * p<0.001$

lecting duct epithelium represents too small of a fraction of the total tissue in this zone. Moreover, this fraction is probably even smaller in diabetes because of proximal tubule hypertrophy [27].

Up regulation of AQP2 could depend directly on the raised vasopressin level because chronic vasopressin infusion in Brattleboro rats was shown to induce a threefold increase in AQP2 protein [28, 29]. The changes in water permeability paralleled the changes in AQP2 protein abundance [28]. Thus, the great upregulation of $\mathrm{AQ} 2$ disclosed here most probably provides the molecular basis for the intense water reabsorption achieved in diabetic rats.

Urea transporters. The UT-A1 is essential for the initial process of medullary urea recycling by permitting urea transfer from terminal collecting duct to papillary interstitium. Another study on 3-day diabetic rats examined only the $97000 \mathrm{M}_{\mathrm{r}}$ isoform and reported a great decrease in the tip and no change in the base of inner medulla [25]. Our study in established diabetes mellitus reveals a clearcut increase in expression UT-A1 in both the base and tip of IM. This regulation occurs most likely at the transcriptional because the abundance in mRNA is incremented in the same proportion as that of the protein in the two inner medullary subregions.

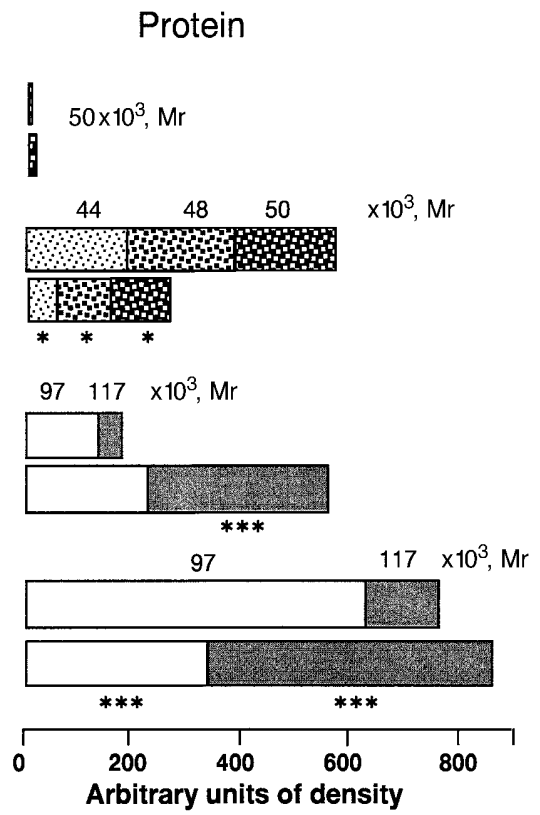

The two glycosylated isoforms of UT-A1 (97000 and $117000 \mathrm{M}_{\mathrm{r}}$ ) both derive from the same non-glycosylated $84000 \mathrm{M}_{\mathrm{r}}$ protein [30]. Our work shows that, in diabetes mellitus, these two isoforms are regulated differently in the different inner medullary subregions. The $97000 \mathrm{M}_{\mathrm{r}}$ protein was not changed in the IM base and greatly underexpressed in IM tip, as has already observed 3 days after streptozotocin injection [25]. It is noteworthy that, among a number of situations in which urinary concentrating activity is altered (alterations in protein or water intake, AVP or dDAVP (V2 agonist) infusion, furosemide treatment [31]), diabetes mellitus is the only one that exhibits a change in the $97000 \mathrm{M}_{\mathrm{r}}$ protein. The $117000 \mathrm{M}_{\mathrm{r}}$ protein was greatly increased in both IM base and tip and thus in both initial and terminal IMCD. Such an increase in the $117000 \mathrm{M}_{\mathrm{r}}$ band has been reported for total inner medulla in several cases of high urine flow rate (furosemide treatment, Brattleboro rats with diabetes insipidus, low protein diet [31]).

The concomitant rise in the $117000 \mathrm{M}_{\mathrm{r}}$ and fall in the $97000 \mathrm{M}_{\mathrm{r}}$ protein isoforms suggests a shift toward a more intense glycosylation of the urea transporter. This could be responsible for a greater transport capacity because, in situations in which the $117000 \mathrm{M}_{\mathrm{r}}$ protein was also shown to be upregulated (water loading, furosemide-induced diuresis, and low protein diet) [31], the basal and vasopressin-stimulated urea permeabilities were also increased [32, 33]. Therefore, in diabetes, the increase in UT-A1 $117000 \mathrm{M}_{\mathrm{r}}$ protein should improve urea reabsorption along the entire IMCD, thereby improving too medullary hypertonicity.

It has been shown that UT-A2 gene expression is under the control of a promoter capable of responding to changes in tonicity $[34,35]$. The UTA2 mRNA was, however, not changed in diabetic 

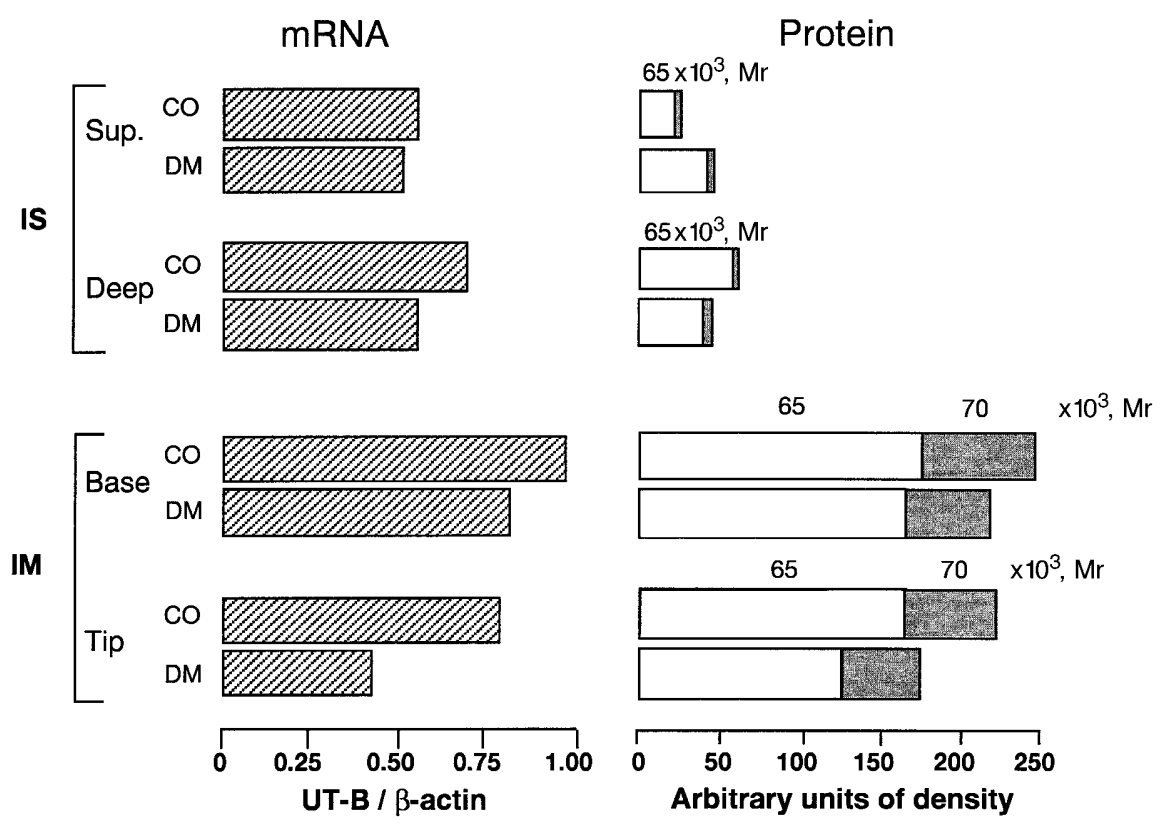

Fig. 5. Densitornetry analysis of UT-B1 mRNA (left) and protein (right) isoform abundance in superficial and deep halves of inner stripe of outer medulla (IS), and in base and tip of inner medulla (IM) of diabetic (DM) and control (CO) rats. The abundance of mRNA is expressed relative to that of $(\beta$-actin. Each column represents the mean of 4-5 rats per group. No significant difference was found between DM and CO rat

rats. Therefore, the observed down-regulation of UTA2 proteins should result from a post-transcriptional regulation. In the case of UT-B1, neither the mRNA nor the protein were affected in diabetes mellitus, suggesting that the amount of UT-B1 is not limiting urea movements in vasa recta.

Functional significance. The factors already known to influence urea transporter expression are those involved in the regulation of water or nitrogen excretion $[13,15,36]$. It is therefore interesting to compare the pathophysiological situation resulting from the metabolic derangements of diabetes with that induced by different concentrations of vasopressin or by alterations in protein intake.

Vasopressin secretion is increased in diabetes mellitus [1-3] and the reabsorption of solute-free water is considerably enhanced. It is thus interesting to evaluate if the changes in UT expression observed in diabetes mellitus resemble those seen in relation with increased water conservation, as induced experimentally in normal rats by chronic infusion of AVP or dDAVP. In fact, they are different. In the case of UT-A1, chronic dDAVP infusion did not induce a change in mRNA and protein expression in whole IM $[31,37]$ in contrast to the considerable increase seen in diabetes mellitus (present study). A recent study showed that chronic dDAVP infusion induced a shift of UT-A1 protein from the tip to the base of IM [38]. In the case of UT-A2, chronic dDAVP infusion in normal rats increased its expression in IS, whereas a fall was observed in this renal zone in diabetic rats. The regulation of UT-B1 also differs in the two cases. A decrease in mRNA abundance in IM and an increase in outer medulla were observed in dDAVP-treated Brattleboro rats [37] but no change occured in diabetic rats.

Thus, in spite of the high plasma vasopressin concentrations and large water reabsorption present in diabetes mellitus, the changes in UTs do not correspond to those observed after intense stimulation of urinary concentrating activity. In fact, an important functional difference exists between these two conditions. In diabetes mellitus, a dramatic increase in osmolar excretion occurs, largely due to glucose, and the relative concentration of urea in urine, as shown by the considerable decrease urine to plasma ratio. In contrast, chronic dDAVP infusion in normal rats is not accompanied by any change in osmolar excretion and the urine to plasma urea ratio is considerably enhanced [39]. The changes in renal urea handling seen in dDAVP-infused rats improve the capacity of the kidney to concentrate urea in the urine whereas those seen in diabetic rats are important for the concentration of glucose in the urine, not for that of urea. Note that urine to blood glucose ratio in diabetic rats reaches a value similar to urine to plasma urea ratio.

Could the changes in UTs occuring in diabetes mellitus represent an adaptation to the altered needs for nitrogen excretion? Urea excretion in diabetic rats is twice as high as in control rats. Thus, renal urea functions in diabetes mellitus could resemble that found in cases of high protein intake. Our study shows that the molecular adaptation seen in diabetes 
mellitus is different because the changes in UT mRNA and protein abundance observed in diabetes mellitus differ from those resulting from protein-rich diet (unchanged mRNA [40], and decreased 117000 $\mathrm{M}_{\mathrm{r}}$ isoform [31]). In contrast, some of the diabetes-induced changes resemble those induced by chronic low protein feeding, such as extension of UTA1 mRNA [41] and vasopressin-dependent urea permeability $[33,42]$ to the initial part of the IMCD, increase in the $117000 \mathrm{M}_{\mathrm{r}}$ isoform [31], and lack of change in UT-A2 and UT-B1 mRNA abundance [40].

At first glance, the similarity of those changes in the urea transporter expression seen in diabetes and chronic low protein feeding seem surprising because these two cases show opposite changes in urea excretory needs. The two cases share some similarities, however, because they both result in a relative deficiency in the amino acids available for metabolic needs, in the first case because of an excess of protein catabolism and in the second case because of an insufficient nitrogen supply. Overexpression of UT-A1 and its appearance in the early IMCD favour the recovery of part of the urea flowing in the collecting duct and its subsequent transfer to the gut where it can be hydrolyzed by microflora endowed with urease, thus allowing the reuse of urea nitrogen by the body $[14,15]$.

Additionally, the increase of glucocorticoids in diabetes mellitus could contribute to UT-A1 changes. Others have shown that the fall in the $97 \mathrm{kD}$ protein in diabetic rats was prevented by adrenalectomy and that dexamethasone replacement reversed this effect $[25,43]$. They excluded insulinopenia and hyperglycaemia as possible causes for these changes [25].

In conclusion, this study shows the molecular changes that accompany the enhanced urine concentrating activity and osmolar excretion associated with uncontrolled diabetes mellitus. The two essential transporters involved in the urinary concentrating process, AQP2 and UT-A1, are overexpressed. The increase of AVP occuring in diabetes mellitus could mediate the up regulation of AQP2 abundance but does not seem to be responsible for that of the urea transporters. The increased expression of these transporters is probably important for water conservation in view of the large amount of glucose excreted in the urine and for nitrogen conservation in view of an excess of protein catabolism.

\section{References}

1. Zerbe RL, Vinicor F, Robertson GL (1979) Plasma vasopressin in uncontrolled diabetes mellitus. Diabetes 28: 503-508

2. Van-Itallie CM, Fernstrom JD (1982) Osmolal effects on vasopressin secretion in the streptozotocin-diabetic rat. Am J Physiol 242: E411-E417
3. Brooks DD, Nutting DF, Crofton JT, Share L (1989) Vasopressin in rats with genetic and streptozotocin-induced diabetes. Diabetes 38: 54-57

4. Kamoi K, Ishibashi M, Yamaji T (1991) Thirst and plasma levels of vasopressin, angiotensin II and atrial natriuretic peptide in patients with non-insulin-dependent diabetes mellitus. Diabetes Res Clin Pract 11: 195-202

5. Tallroth G, Ryding E, Ekman R, Agardh CD (1992) The response of regulatory peptides to moderate hypoglycaemia of short duration in Type 1 (insulin-dependent) diabetes mellitus and in normal man. Diabetes Res 20: 73-85

6. Iwasaki Y, Kondo K, Murase T, Hasegawa H, Oiso Y (1996) Osmoregulation of plasma vasopressin in diabetes mellitus with sustained hyperglycemia. J Neuroendocrinol 8: 755-760

7. Phillips PA, Risvanis J, Hutchins A-M, Burrell LM, MacGregor D, Gundlach AL, Johnston CI (1995) Down-regulation of vasopressin V1 a receptor mRNA in diabetes mellitus in the rat. Clin Sci (Colch) 88: 671-674

8. Trinder D, Phillips PA, Stephenson JM et al. (1994) Vasopressin V1 and V2 receptors in diabetes mellitus. Am J Physiol 266: E217-E223

9. Ahloulay M, Schmitt F, Dechaux M, Bankir L (1999) Vasopressin and urinary concentrating activity in diabetes mellitus. Diabetes Metab 25: 213-222

10. Bardoux P, Martin H, Ahloulay M et al. (1999) Vasopressin contributes to hyperfiltration, albuminuria, and renal hypertrophy in diabetes mellitus: study in vasopressin-deficient Brattleboro rats. Proc Natl Acad Sci USA 96: 10397-10402

11. Knepper MA, Roch-Ramel F (1987) Pathways of urea transport in the mammalian kidney. Kidney Int 31: 629-633

12. Hediger MA, Smith CP, You G, Lee WS, Kanai Y, Shayakul C (1996) Structure, regulation and physiological roles of urea transporters. Kidney Int 49: 1615-1623

13. Sands JM, Timmer RT, Gunn RB (1997) Urea transporters in kidney and erythrocytes. Am J Physiol 273: F321-F339

14. Trinh-Trang-Tan MM, Bankir L (1998) Integrated function of urea transporters in the mammalian kidney. Exp Nephrol 6: 471-479

15. Bankir L, Trinh-Trang-Tan MM (2000) Urea and the kidney. In: Brenner BM, Rector FC (eds) The Kidney 6th Edn. WB Saunders Company, Philadelphia, pp 637-679

16. Nielsen S, Terris J, Smith CP, Hediger MA, Ecelbarger CA, Knepper MA (1996) Cellular and subcellular localization of the vasopressin-regulated urea transporter in rat kidney. Proc Natl Acad Sci U S A 93: 5495-5500

17. Xu Y, Olives B, Bailly P et al. (1997) Endothelial cells of the kidney vasa recta express the urea transporter HUT11. Kidney Int 51: 138-146

18. Shayakul C, Knepper MA, Smith CP, DiGiovanni SR, Hediger MA (1997) Segmental localization of urea transporter mRNAs in rat kidney. Am J Physiol 272: F654-F660

19. Sands JM, Nonoguchi H, Knepper MA (1987) Vasopressin effects on urea and $\mathrm{H} 2 \mathrm{O}$ transport in inner medullary collecting duct subsegments. Am J Physiol 253: F823-F832

20. Promeneur D, Rousselet G, Bankir L, Bailly P, Cartron JP, Ripoche P, Trinh-Trang-Tan MM (1996) Evidence for distinct vascular and tubular urea transporters in the rat kidney. J Am Soc Nephrol 7: 852-860

21. Couriaud C, Ripoche P, Rousselet G (1996) Cloning and functional characterization of a rat urea transporter: expression in the brain. Biochim Biophys Acta 1309: 197-199

22. Alonso S, Minty A, Bourlet Y, Buckingham M (1986) Comparison three actin-coding sequences in mouse: evolutionary relationships between the actin genes of warm-blooded vertebrates. J Mol Evol 23: 11-22 
23. Hu MC, Bankir L, Michelet S, Rousselet G, Trinh-TrangTan MM (2000) Massive reduction of urea transporters in remnant kidney and brain of uremic rats. Kidney Int 58: 1202-1210

24. Valenti G, Frigeri A, Ronco PM, D'Ettorre C, Svelto M (1996) Expression and functional analysis of water channels in a stably AQP2-transfected human collecting duct cell line. J Biol Chem 271: 24365-24370

25. Klein JD, Price SR, Bailey JL, Jacobs JD, Sands JM (1997) Glucocorticoids mediate a decrease in AVP-regulated urea transporter in diabetic rat inner medulla. Am J Physiol 273: F949-F953

26. Nejsum LN, Marples D, Kwon TH et al. (1999) Increased AQP2 expression and targeting in rats with severe osmotic diuresis in response to streptozotocin-induced diabetes mellitus. J Am Soc Nephrol 10: 21A (Abstract)

27. Rasch R, Dorup J (1997) Quantitative morphology of the rat kidney during diabetes mellitus and insulin treatment. Diabetologia 40: 802-809

28. DiGiovanni SR, Nielsen S, Christensen EL, Knepper MA (1994) Regulation of collecting duct water channel expression by vasopressin in Brattleboro rat. Proc Natl Acad Sci USA 91: 8984-8988

29. Kishore BK, Terris JM, Knepper MA (1996) Quantitation of aquaporin-2 abundance in microdissected collecting ducts: axial distribution and control by AVP. Am J Physiol 271: F62-F70

30. Rouillard P, Klein JD, Timmer RT, Sands JM (1998) Glycosylated forms of UT-A urea transporters present in kidney medulla. J Am Soc Nephrol 9: 25A (Abstract)

31. Terris J, Ecelbarger CA, Sands JM, Knepper MA (1998) Long-term regulation of renal urea transporter protein expression in rat. J Am Soc Nephrol 9: 729-736

32. Kato A, Naruse M, Knepper MA, Sands JM (1998) Longterm regulation of inner medullary collecting duct urea transport in rat. J Am Soc Nephrol 9: 737-745

33. Kato A, Sands JM (1999) Urea transport processes are induced in rat IMCD subsegments when urine concentrating ability is reduced. Am J Physiol 276: F62-F71
34. Leroy C, Basset G, Gruel G, Ripoche P, Trinh-Trang-Tan MM, Rousselet G (2000) Hyperosmotic $\mathrm{NaCl}$ and urea synergistically regulate the expression of the UT-A2 urea transporter in vitro and in vivo. Biochem Biophys Res Commun 271: 368-373

35. Nakayama Y, Peng T, Sands JM, Bagnasco SM (2000) The TonE/TonEBP pathway mediates tonicity-responsive regulation of UT-A urea transporter expression. J Biol Chem 275: 38275-38280

36. Tsukaguchi H, Shayakul C, Berger UV, Hediger MA (1998) Urea transporters in kidney: molecular analysis and contribution to the urinary concentrating process. Am J Physiol 275: F319-F324

37. Promeneur D, Bankir L, Hu MC, Trinh-Trang-Tan MM (1998) Renal tubular and vascular urea transporters: influence of antidiuretic hormone on messenger RNA expression in Brattleboro rats. J Am Soc Nephrol 9: 1359-1366

38. Trinh-Trang-Tan MM, Ugnon-Cafe S, Bankir L, Rousselet G (2000) dDAVP promotes a shift in UT-A1 expression from terminal to initial inner medullary collecting duct (IMCD). J Am Soc Nephrol 11: 23A (Abstract)

39. Bouby N, Ahloulay M, Nseghe E, Déchaux M, Schmitt F, Bankir L (1996) Vasopressin increases glomerular filtration rate in conscious rats through its antidiuretic action. J Am Soc Nephrol 7: 842-851

40. Hu MC, Bankir L, Trinh-Trang-Tan MM (1999) mRNA expression of renal urea transporters in normal and Brattleboro rats: effect of dietary protein intake. Exp Nephrol 7: 44-51

41. Smith CP, Lee WS, Martial S et al. (1995) Cloning and regulation of expression of the rat kidney urea transporter (rUT2). J Clin Invest 96: 1556-1563

42. Isozaki T, Verlander JW, Sands JM (1993) Low protein diet alters urea transport and cell structure in rat initial inner medullary collecting duct. J Clin Invest 92: 2448-2457

43. Naruse M, Klein JD, Ashkar ZM, Jacobs JD, Sands JM (1997) Glucocorticoids downregulate the vasopressin-regulated urea transporter in rat terminal inner medullary collecting ducts. J Am Soc Nephrol 8: 517-523 